\title{
Enhanced Mechanical Properties of Polyvinyl Chloride-Based Wood-Plastic Composites With Pretreated Corn Stalk
}

\author{
Tao Shen ${ }^{1,2}$, Minghui $L i^{1}$, Bo Zhang ${ }^{1}$, Lingxia Zhong ${ }^{1}$, Xiran Lin ${ }^{1}$, Pengpeng Yang ${ }^{1}$, Ming Li ${ }^{1 *}$, \\ Wei Zhuang ${ }^{1 *}$, Chenjie Zhu ${ }^{1}$ and Hanjie Ying ${ }^{1,3}$ \\ ${ }^{1}$ College of Biotechnology and Pharmaceutical Engineering, Nanjing Tech University, Nanjing, China, ${ }^{2}$ College of Food Science \\ and Light Industry, Nanjing Tech University, Nanjing, China, ${ }^{3}$ School of Chemical Engineering, Zhengzhou University, Zhengzhou, \\ China
}

\section{OPEN ACCESS}

Edited by:

Caoxing Huang,

Nanjing Forestry University, China

Reviewed by:

Rijia Lin,

The University of Queensland,

Australia

Rongxian $\mathrm{Ou}$,

South China Agricultural University,

China

Xuefei Cao,

Beijing Forestry University, China

*Correspondence:

Ming Li

m.li@njtech.edu.cn

Wei Zhuang

weizhuang@njtech.edu.cn

Specialty section:

This article was submitted to Bioprocess Engineering,

a section of the journal

Frontiers in Bioengineering and

Biotechnology

Received: 06 December 2021

Accepted: 20 December 2021

Published: 24 January 2022

Citation:

Shen T, Li M, Zhang B, Zhong L, Lin X, Yang $P$, Li M, Zhuang $W$, Zhu $C$ and Ying $H$ (2022) Enhanced Mechanical

Properties of Polyvinyl Chloride-Based

Wood-Plastic Composites With

Pretreated Corn Stalk.

Front. Bioeng. Biotechnol. 9:829821.

doi: 10.3389/fbioe.2021.829821
Wood-plastic composites (WPCs) are a type of environmentally friendly materials widely used in daily life. This paper selected low-value biomass, corn stalk (CS), as the lignocellulosic resource for polyvinyl chloride (PVC)-based WPCs. To depict the relationship between lignocellulosic composition (cellulose, hemicellulose, and lignin) and mechanical performance of WPCs, pretreatments have been optimized to selective removal of lignin using an alkaline-EtOH stewing process and selective removal of hemicellulose using an acid stewing process. The $\mathrm{aC}$ sample, in which both lignin and hemicellulose were removed, shows the highest degree of crystallinity (72.60\%) as estimated from X-ray diffraction analysis results and fibrous morphology with the highest aspect ratio as seen in scanning electron microscopy images. Compared with PVC/CS, PVC/aC gives a substantial increase in tensile strength and modulus by 37.21 and $21.66 \%$ and flexural strength and modulus by 29.98 and $34.88 \%$, respectively. These improvements lie in the reinforcing effect of a fibrous structure and the improved interfacial compatibility as proven by scanning electron microscopy and dynamic mechanical analyzer results. Considering the extracted lignin and hemicellulose can be further developed to valuable biochemicals, the pretreatment to CS adds value to both WPC materials and biorefinery products.

Keywords: wood-plastic composites, polyvinyl chloride, lignocellulose, pretreatment, mechanical properties

\section{INTRODUCTION}

The environmental and climate problems caused by massive petroleum consumption have accumulated to a stage where people have to respond quickly. The global plastic demands are approximately $300 \mathrm{Mt} / \mathrm{year}$ nowadays (Liminana et al., 2018) and are still dominantly fulfilled by petroleum-based plastics. To replace petroleum-based plastics, at least partially, with materials from renewable resources or bio-based wastes is one practical approach to reduce the carbon footprint (Tahir et al., 2017; Andreeßen and Steinbüchel, 2019; Quiles-Carrillo et al., 2019). Wood-plastic composites (WPCs) composed of thermoplastics and wood powders have been developed since the 1990 s and are nowadays widely applied as furniture and domestic/outdoor building materials (Liu et al., 2019; Sun et al., 2019; Mu et al., 2021). WPCs are generally regarded as a type of 
environmentally friendly materials due to their partial biomass origin. Low-value lignocellulosic biomass, e.g., corn stalk (CS), and recycled thermoplastics, can also be involved to minimize carbon footprint.

High-density polyethylene and polypropylene were most exploited as the thermoplastic matrix for WPCs due to their high production amount, high durability, and ease of processing (Tserki et al., 2005; Hao et al., 2020). Lignocellulose is mainly composed of cellulose, hemicellulose, and lignin, each playing a particular structural role and self-assembled to support the plant (Boerjan et al., 2003). Their compositions vary depending on the origin of the resource and therefore impose influences on the properties of the resulting WPCs (Nourbakhsh and Ashori, 2010). WPCs filled with highly crystalline lignocellulosic fibers showed significantly improved tensile, flexural, and impact properties (Michell et al., 1976; Tian et al., 2009; Ashori and Nourbakhsh, 2010). Filling with hemicellulose-extracted lignocellulose could improve the tensile strength and water resistance of the composites (Enayati et al., 2009; Hosseinaei et al., 2012). Incorporation of lignin or modified lignin into WPCs has found improvement in weatherability and thermal stability (Kharade and Kale 1999; Maldhure et al., 2012).

Lignocellulose contains large amounts of polar functionalities (e.g., -OH), especially in the cellulose and hemicellulose components. Therefore, the lignocellulose is basically incompatible with the hydrophobic polyolefin matrix (AlvarezValencia et al., 2010; Ayrilmis et al., 2011) and results in poor interfacial adhesion between the lignocellulose and thermoplastics domains and inefficient stress transfer from the ductile matrix to the rigid lignocellulose reinforcements (Kazayawok et al., 1999; Chaharmahali et al., 2008). To enhance the mechanical properties of the composites, compatibilizers such as ethylene-acrylic acid copolymer (Szabo et al., 2018), ethylene-vinyl acetate copolymer (Alexy et al., 2004), maleic anhydride (Cazacu et al., 2004), and grafting modifiers (Casenave et al., 1995) were explored as functional additives.

Polyvinyl chloride (PVC) is another type of thermoplastics extensively used in daily life. Compared with high-density polyethylene and polypropylene, it contains non-protonic polar C-Cl bonds in its macromolecules, which impart higher compatibility with the lignocellulosic fillers. Due to the intrinsic flame retardance of PVC, PVC-based WPCs are especially suitable for domestic applications. Researchers studied a few PVC-based WPCs with various lignocellulose resources, including eucalyptus wood, rice husk, bamboo, CS, and sisal (Petchwattana et al., 2012; Chen et al., 2017; Chen J. et al., 2018; Zong et al., 2020; Qi et al., 2021). Wood flour treated with an aminosilane modifier was reported to provide improved mechanical properties (Yim and Kim, 2012). However, the research about PVC-based WPCs is far less intensive compared with that for polyolefin-based WPCs. It is still unclear how the composition in lignocellulose plays a role in the mechanical performance of PVC-based WPCs.

In this paper, low-value biomass, CS, has been selected as the lignocellulosic resource for PVC-based WPCs. To distinguish the contribution of the components (cellulose, hemicellulose, and lignin), pretreatments have been optimized to selective removal of hemicellulose or/and lignin from CS. The raw CS and the residue compounds have been examined to analyze their composition, structure, and morphology. PVC-based WPCs have been prepared with the raw $\mathrm{CS}$ and the residue compounds as fillers and characterized to depict the relationship between lignocellulosic composition and mechanical performance of the resulting WPCs.

\section{EXPERIMENTAL AND MATERIALS}

\section{Materials}

Pretreatment reagents and processing additives were purchased from Aladdin Company. PVC was purchased from Tianye Group, China. CS was obtained from a local factory in Lianyungang, China, which was smashed and screened to 40-60 mesh and dried at $100^{\circ} \mathrm{C}$ to constant weight. The composition of the raw CS (on a dry weight basis) is $35.90 \mathrm{wt}$ $\%$ of cellulose, $24.8 \mathrm{wt} \%$ of hemicellulose, $19.7 \mathrm{wt} \%$ of lignin, $3.9 \mathrm{wt} \%$ of ash, and $15.7 \mathrm{wt} \%$ of unknown components.

\section{Methods}

\section{Characterization of Lignocellulose}

The composition of lignocellulose samples was analyzed according to National Renewable Energy Laboratory procedures (Sluiteret al., 2008). The acid hydrolysate was quantified by high-performance liquid chromatography (Waters 1525-2414) with a refractive index detector, using an Aminex HPX-87H ion exclusion column $(300 \times$ $7.8 \mathrm{~mm}$; Bio-Rad Laboratories, Hercules, CA, USA). The mobile phase was $5.0-\mathrm{mM} \mathrm{H}_{2} \mathrm{SO}_{4}$ at a flow rate of $0.6 \mathrm{ml} \mathrm{min}^{-1}$; the temperature of the column was $55^{\circ} \mathrm{C}$. Lignin was determined by gravimetric analysis (calcined acid-insoluble residue at $575^{\circ} \mathrm{C}$ for $24 \mathrm{~h}$ ) and ultraviolet-visible spectroscopy.

Fourier-transform infrared spectroscopy (FT-IR) analysis was conducted using Thermo Scientific IS-5 with a universal attenuated total reflection accessory. FT-IR spectra were collected from 4,000 to $500 \mathrm{~cm}^{-1}$ for 16 scans. Morphology analysis was conducted using a scanning electron microscope (SEM, FEI Quanta 200 FEG SEM) at $2 \mathrm{kV}$ and 5,000 magnification. Thermogravimetric analysis (Netzsch STA 449F3) of lignocellulosic samples was conducted from 25 to $600^{\circ} \mathrm{C}$

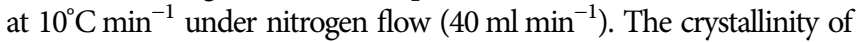
lignocellulosic samples was characterized by an X-ray diffractometer (Bruker D8). The samples of particle size less than 100 mesh were scanned from 10 to 40 at a speed of $10^{\circ} \mathrm{min}^{-1}$ in the $40-\mathrm{kV}$ voltage and 40-mA current.

\section{Characterization of Wood-Plastic Composites}

The dynamic mechanical properties of WPCs were characterized by the dynamic mechanical analyzer (DMA 450, France, Metravib). The samples $(20 \times 8 \times 3 \mathrm{~mm})$ were scanned in a tensile mode at $1 \mathrm{~Hz}$ with a strain amplitude of $15 \mu \mathrm{m}$, in a temperature range from 25 to $140^{\circ} \mathrm{C}$ at $3^{\circ} \mathrm{C} \mathrm{min}^{-1}$. The tensile and flexural properties of WPCs were characterized using a universal testing machine according to the GB/T 1040.2-2006. The dumbbell tensile samples $(160 \times 20 \times 4 \mathrm{~mm})$ were tested at a tensile rate of $5 \mathrm{~mm} \mathrm{~min}^{-1}$. The flexural samples $(80 \times 10 \times 4 \mathrm{~mm})$ were tested at a rate of $2 \mathrm{~mm} \mathrm{~min}^{-1}$. 
TABLE 1 | Delignification conditions and the corresponding composition analysis.

\begin{tabular}{|c|c|c|c|c|c|c|c|c|c|c|}
\hline \multirow[t]{2}{*}{ Entries } & \multicolumn{3}{|c|}{ Pretreating conditions } & \multirow{2}{*}{$\begin{array}{c}\text { Residue/ } \\
\%\end{array}$} & \multicolumn{3}{|c|}{ Composition/\% } & \multirow[t]{2}{*}{ Delignification rate/\% } & \multicolumn{2}{|c|}{ Retention rate/\% } \\
\hline & $\begin{array}{c}\mathrm{NaOH} / \\
\mathbf{w} \%\end{array}$ & $\mathrm{EtOH} / \mathrm{H}_{2} \mathrm{O}$ v\% & $\begin{array}{c}\text { Temp./ } \\
{ }^{\circ} \mathbf{C}\end{array}$ & & Cellulose & Hemicellulose & Lignin & & Cellulose & Hemicellulose \\
\hline 1 & 0 & $60 / 40$ & 130 & 74.8 & 45.82 & 28.04 & 15.63 & 40.66 & 95.46 & 84.56 \\
\hline 2 & 4 & $60 / 40$ & 130 & 64.2 & 52.16 & 30.56 & 6.47 & 78.93 & 93.27 & 79.12 \\
\hline 3 & 8 & $60 / 40$ & 130 & 52.4 & 60.82 & 28.54 & 4.84 & 83.78 & 88.77 & 60.31 \\
\hline 4 & 8 & $80 / 20$ & 130 & 53.6 & 61.63 & 33.77 & 1.54 & 87.23 & 92.01 & 72.98 \\
\hline 5 & 8 & $80 / 20$ & 150 & 57.8 & 56.63 & 23.18 & 0.75 & 91.01 & 91.17 & 54.03 \\
\hline $6^{\mathrm{a}}$ & 8 & $80 / 20$ & 130 & 58.5 & 58.15 & 34.92 & 0.26 & 89.98 & 94.69 & 82.32 \\
\hline
\end{tabular}

${ }^{a} 1$ wt\% anthraquinone added.

TABLE 2 | Acid stewing conditions and the corresponding composition analysis.

\begin{tabular}{|c|c|c|c|c|c|c|c|c|c|}
\hline \multirow[t]{2}{*}{ Entries } & \multicolumn{2}{|c|}{ Conditions } & \multirow[t]{2}{*}{ Residue/\% } & \multicolumn{3}{|c|}{ Composition/\% } & \multirow{2}{*}{$\begin{array}{c}\text { Removal rate } \\
\text { of hemicellulose/\% }\end{array}$} & \multicolumn{2}{|c|}{ Retention rate/\% } \\
\hline & $\mathrm{pH}$ & Time/min & & Cellulose & Hemicellulose & Lignin & & Cellulose & Lignin \\
\hline 1 & 5.0 & 30 & 60.2 & 56.12 & 14.19 & 28.88 & 65.55 & 94.11 & 88.25 \\
\hline 2 & 5.5 & 30 & 58.4 & 59.30 & 17.57 & 29.45 & 58.63 & 96.46 & 87.29 \\
\hline 3 & 5.5 & 60 & 50.8 & 66.46 & 6.19 & 34.02 & 87.32 & 94.04 & 87.72 \\
\hline
\end{tabular}

\section{Experimental}

\section{Pretreatment of Corn Stalk}

Typically, 1-kg CS was placed in a 10-L autoclave with $6 \mathrm{~L}$ of $80 /$ $20 \mathrm{vt} \%$ ethanol/water, $8 \mathrm{wt} \% \mathrm{NaOH}$, and $1 \mathrm{wt} \%$ anthraquinone and pretreated at $130^{\circ} \mathrm{C}$ for 60 min under stirring to selectively remove the lignin component. Afterward, the mixture was filtrated and washed with deionized water to be neutral, and the residue was dried and labeled as $\mathrm{HC}$.

Typically, 1-kg CS was placed in a 10-L autoclave with $6 \mathrm{~L}$ of deionized water. The $\mathrm{pH}$ of the mixture was adjusted to 5.5 using $72 \mathrm{wt} \% \mathrm{H}_{2} \mathrm{SO}_{4}$. The mixture was stirred at $150^{\circ} \mathrm{C}$ for $60 \mathrm{~min}$ to selectively remove the hemicellulose component. Afterward, the mixture was filtrated and washed with deionized water to be neutral, and the residues were dried and labeled as HR.

\section{Preparation of Wood-Plastic Composites}

Typically, the CS was dried at $105^{\circ} \mathrm{C}$ for $24 \mathrm{~h}$ before use. WPC was prepared according to the following formulation: 1,000 $\mathrm{g}$ of PVC, $200 \mathrm{~g}$ of CS, $60 \mathrm{~g}$ of Ca-Zn stearate, $30 \mathrm{~g}$ of acrylate copolymer, $100 \mathrm{~g}$ of chlorinated polyethylene, $5 \mathrm{~g}$ of stearic acid, and $4 \mathrm{~g}$ of polyethylene wax. The components mentioned earlier were first mixed in a high-speed blender, then melt-compounded using a twin-roll miller at $175^{\circ} \mathrm{C}$ for 5-10 min, and finally, compressionmolded at $185^{\circ} \mathrm{C}$ for $5 \mathrm{~min}$.

\section{RESULTS AND DISCUSSION}

\section{Pretreatment of Corn Stalk}

To selectively delignify CS with maximum removal of lignin and highest retention of cellulose and hemicellulose, we explored the delignification of CS using alkaline-organic solvent stewing method as inspired by previous studies (Tang et al., 2017;
Chen X. et al., 2018; Zhong et al., 2018; Chen et al., 2019). As shown in Table 1, pretreatment systems with different concentrations of $\mathrm{NaOH}$ and $\mathrm{EtOH}$ were evaluated in removal rate of lignin and retention rate of cellulose and hemicellulose. The residue compound, labeled as $\mathrm{HC}$, were examined using the National Renewable Energy Laboratory procedures to quantify each component (cellulose, hemicellulose, and lignin). As shown in Entries 1-3, simply increasing the concentration of $\mathrm{NaOH}$ from $0 \%$ to $8 \mathrm{w} \%$ led to a higher delignification rate, but the retention rate of cellulose and hemicellulose decreased rapidly, which is not desirable. In Entry 4, the amount of EtOH was increased to $80 \mathrm{v} \%$ compared with that in Entry 3 (60 v\%). The delignification rate was improved to $87.23 \%$, whereas the retention rate of cellulose and hemicellulose also moderately increased. When we elevated the stewing temperature to $150^{\circ} \mathrm{C}$, as shown in Entry 5, the delignification rate reached a maximum, but the retention rate of hemicellulose significantly decreased, suggesting that hemicellulose is more sensitive to harsher temperatures. Anthraquinone has been reported to be able to oxidize the aldehyde end-groups of cellulose and hemicellulose and to retard the exfoliation of the carbohydrate components during the pretreatment (Nascimento et al., 2016). To further improve the retention rate of cellulose and hemicellulose, we added $1 \mathrm{wt} \%$ anthraquinone to the stewing system of Entry 4 and achieved a delignification rate of $89.98 \%$, and the retention rates of cellulose and hemicellulose were 94.69 and $82.32 \%$, respectively. Therefore, the optimal delignification conditions can be regarded as $8 \mathrm{wt} \% \mathrm{NaOH}, 80 \mathrm{vt} \%$ ethanol solution, and $1 \%$ anthraquinone at $130^{\circ} \mathrm{C}$ for $60 \mathrm{~min}$.

Hemicellulose is one of the main components in lignocellulose and can be hydrolyzed to pentose under acid stewing conditions (Li et al., 2020; Shen et al., 2020; Sun et al., 2021). To selectively remove the hemicellulose component, CS was pretreated via acid 


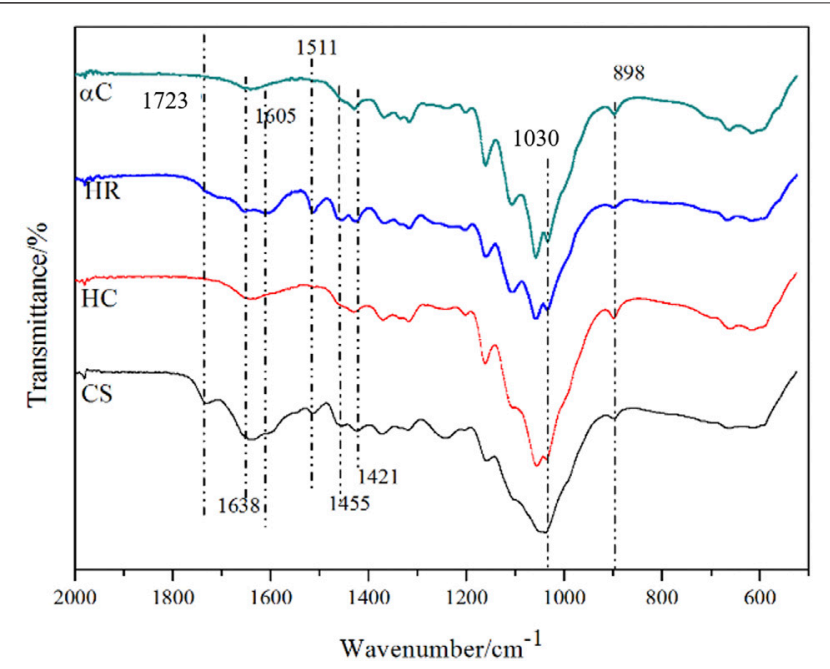

FIGURE 1 | Fourier-transform infrared spectroscopy spectra results of $a \mathrm{C}, \mathrm{HR}, \mathrm{HC}$, and $\mathrm{CS}$.

stewing at $150^{\circ} \mathrm{C}$ with different $\mathrm{pH}$ and stewing times, and the resulting residue compound was labeled as HR. Table 2 shows the pretreatment conditions and the corresponding results of composition analysis. Compared with a pretreating system of pH 5.0 (Entry 1), the system of pH 5.5 (Entry 2) gave an inferior decrease in removing hemicellulose but a slightly higher retention rate of cellulose. When we extended the stewing time from 30 to 60 min (Entry 3), the removal rate of hemicellulose dramatically increased to $87.32 \%$, and meanwhile, a reasonably high retention rate of cellulose (94.04\%) and lignin (87.72\%) was still obtained. Also, considering the corrosion to equipment and difficulty in dealing with acidic wastewater, a higher $\mathrm{pH}$ is preferable. Therefore, the optimal condition for selective removal of hemicellulose was regarded as acid stewing at $\mathrm{pH} 5.5$ for $60 \mathrm{~min}$. To obtain both lignin- and hemicellulose-removed samples, CS was pretreated consecutively with the conditions of Entry 6 in Table 1 and the conditions of Entry 3 in Table 2. The resulted compound was labeled as $\mathrm{aC}$ and examined to contain $78.27 \mathrm{wt} \%$ of cellulose, $2.97 \mathrm{wt} \%$ of hemicellulose, and $5.52 \mathrm{wt} \%$ of lignin.

\section{Analysis of Pretreated Corn Stalk}

FT-IR was used to characterize $\mathrm{CS}, \mathrm{HC}, \mathrm{HR}$, and $\mathrm{aC}$ as shown in Figure 1, and the attribution of characteristic peaks is summarized in Table 3. The spectra for $\mathrm{HC}$ and $\mathrm{aC}$ are highly similar because these two samples are mainly composed of polysaccharides. The characteristic peaks for lignin at 1,723 $\left(\mathrm{C}=\mathrm{O}\right.$ ), 1,605, 1,511, and $1,455 \mathrm{~cm}^{-1}$ (aromatic ring skeleton vibration in lignin) are obviously found in CS and HR but vanish for $\mathrm{HC}$ and $\mathrm{aC}$, indicating that in these two samples, lignin was effectively removed. These results are consistent with the composition analysis data (Tables 1 and 2).

The morphology of CS, HC, HR, and $\mathrm{aC}$ was characterized by SEM, as shown in Figure 2. The original CS sample shows large sheets or blocks, whereas the pretreated samples exhibit cylindrical or fibrous shapes with smaller sizes and higher aspect ratios, especially for the aC sample revealing thin fiberlike morphology with the highest aspect ratio. Lignin and hemicellulose are generally regarded as adhesives to glue the cellulose fibrils in the plant cell walls, and the removal of these components leaves more cellulose fibrils exposed, as presented in the SEM image of aC. Because lignin is not directly bonded to cellulose molecules, the $\mathrm{HC}$ sample with selective removal of lignin still presents thick sheets and blocks rather than thin fibers.

The crystal form of cellulose in all these samples was detected and analyzed by X-ray diffraction analysis, as shown in Figure 3. As previously reported, the crystal type I of cellulose gives characteristic $2 \theta$ diffractions at 16.5 and $22.5^{\circ}$ (Segal et al., 1959), which can also be seen in all samples, suggesting that the crystal form of cellulose did not change during the pretreatment. The degree of crystallinity (Cr I) for each sample was estimated based on the intensity of characteristic diffractions (Eq. 1) (Segal et al., 1959).

$$
\operatorname{Cr} I(\%)=\left(I_{002}-I_{a m}\right) / I_{002} \times 100 \% .
$$

where $I_{002}$ is the intensity for the $2 \theta$ diffraction at $22.5^{\circ} ; I_{a m}$ is the intensity for the $2 \theta$ diffraction at $16.5^{\circ}$. The aC sample shows the highest degree of crystallinity $(72.60 \%)$, which is in line with its highest content of cellulose and the highest aspect ratio (Ouajai and Shanks, 2005). HR exhibits a degree of crystallinity of 53.90\%, higher than that for CS $(42.18 \%)$. These results confirm that removing the amorphous lignin and hemicellulose components enriches cellulose in the residue compounds, leading to a higher degree of crystallinity. However, HC contains $58.15 \mathrm{wt} \%$ of cellulose, much higher than that for CS (35.90 wt\%), but shows a similar degree of crystallinity (42.23\%), suggesting that a large proportion of crystalline cellulose has been disordered and turned into amorphous cellulose during the alkaline-organic solvent stewing process.

TABLE 3 | Assignment of Fourier-transform infrared spectroscopy absorption.

\begin{tabular}{ll}
\hline 1,723 & Unconjugated carbonyl C=O stretching \\
1,638 & $\mathrm{O}-\mathrm{H}$ \\
$1,605,1,511$, and 1,455 & Aromatic ring skeleton vibration \\
1,421 & $\mathrm{C}-\mathrm{H}$ bending \\
1,030 & $\mathrm{C}-\mathrm{O}-\mathrm{C}$ stretching \\
898 & $\beta-$ glycosidic bond stretching
\end{tabular}

Lignin

Bound $\mathrm{H}_{2} \mathrm{O}$

Lignin

Lignin and polysaccharides

Polysaccharides

Cellulose 

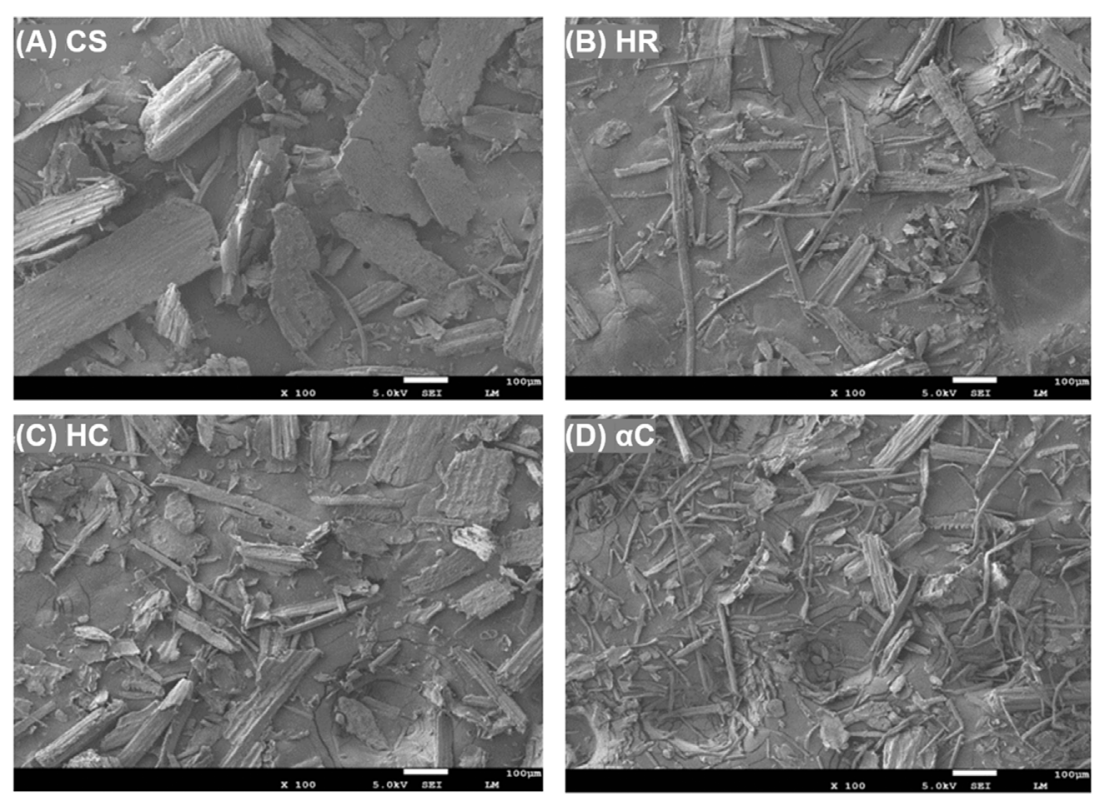

FIGURE 2 | SEM of different lignocellulose components (A) CS, (B) HC, (C) HR, and (D) aC.

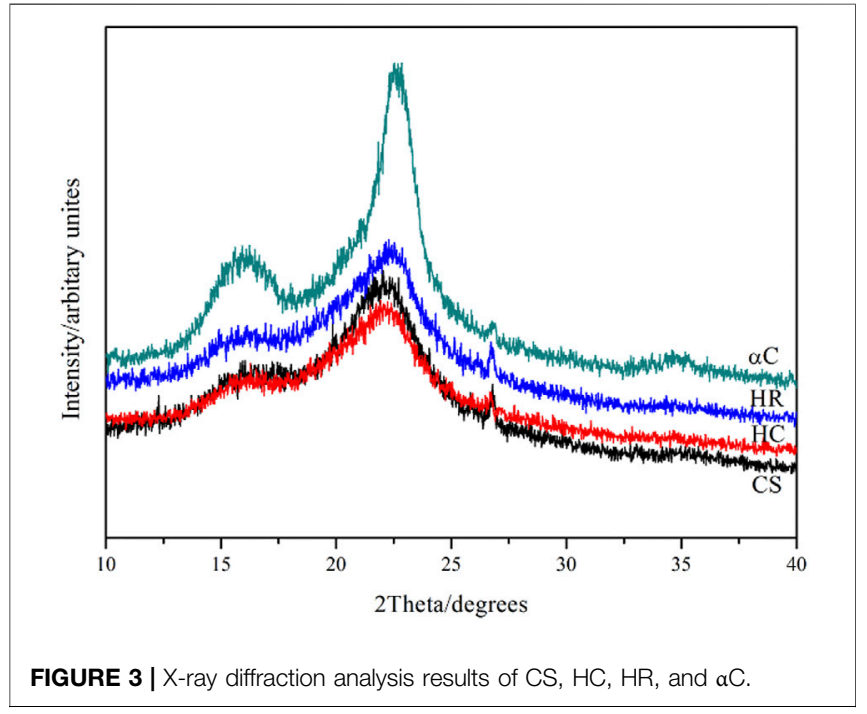

The thermal stability of CS, HC, HR, and $\mathrm{aC}$ was studied by thermogravimetric analysis, as shown in Figure 4. All samples give a slight weight loss at $<100^{\circ} \mathrm{C}$, which was attributed to moisture evaporation. When the temperature reaches above $200^{\circ} \mathrm{C}$, the decomposition process gradually speeds up as hemicellulose and low molecular weight component such as phytowax; oligosaccharides start to degrade and leave. This is especially prominent for the CS sample because it was not pretreated and retains a higher amount of low molecular weight components. This decomposition stage for the HC sample took place at a lower temperature than those for the $\mathrm{HR}$ and $\mathrm{aC}$ samples because it was delignified and contained a higher amount of hemicellulose than the other two. When the temperature reached $270-380^{\circ} \mathrm{C}$, the glycosidic bond in cellulose cleaves and the $\mathrm{C}$ - $\mathrm{O}$ bond in lignin also breaks up, resulting in rapid weight loss for all samples (Gibson, 2016), reaching a maximum loss rate at $315^{\circ} \mathrm{C}$ for the $\mathrm{CS}$ sample, $331^{\circ} \mathrm{C}$ for the $\mathrm{HC}$ and $\mathrm{aC}$ sample, and $351^{\circ} \mathrm{C}$ for the HR sample. The residue weight reached a plateau at $>380^{\circ} \mathrm{C}$ for the $\mathrm{HC}$ and $\mathrm{aC}$ samples, whereas the weight loss for HR and CS is still slowly taking place. This weight loss is attributed to the ongoing degradation of the lignin component where the $\mathrm{C}-\mathrm{C}$ backbone breaks up at this temperature range. The HR sample with selective removal of hemicellulose has the highest content of lignin, and therefore, its DTG peak shifted to a higher temperature range.

\section{Morphology and Mechanical Properties of Wood-Plastic Composites}

To investigate the effect of lignocellulosic compositions on the properties of PVC-based composites, WPC samples filled with CS, $\mathrm{HC}, \mathrm{HR}$, and $\mathrm{\alpha C}$ were prepared by traditional thermal compounding and compression molding techniques (Liu et al., 2014). The mass ratio of the PVC matrix and the filler was controlled to be 100:20. Necessary functional additives such as thermal stabilizer (Ca-Zn stearate), lubricants (stearic acid and polyethylene wax), and toughening modifiers (acrylate copolymer and chlorinated polyethylene) were blended in before thermal compounding.

The tensile and flexural properties of WPCs are shown in Figure 5. Compared with the PVC/CS sample, the WPC samples with $\mathrm{HC}, \mathrm{HR}$, and $\mathrm{aC}$ show similar elongation at break (3.80-4.95\%) but higher tensile and bending performance in both strength and modulus. The reinforcing effect in the PVC/ aC sample is especially prominent, showing a significant increase in tensile strength and modulus by 37.21 and $21.66 \%$ and in flexural strength and modulus by 29.98 and $34.88 \%$, respectively. 

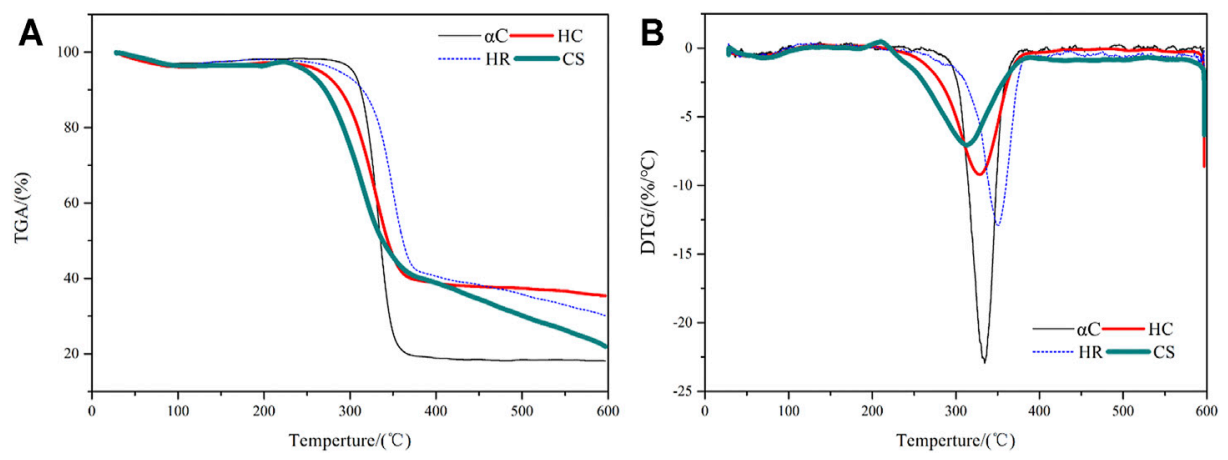

FIGURE 4 | Thermal analysis of CS, HC, HR, and $\mathrm{aC}$ (A) thermogravimetric analysis results; (B) DTG results.
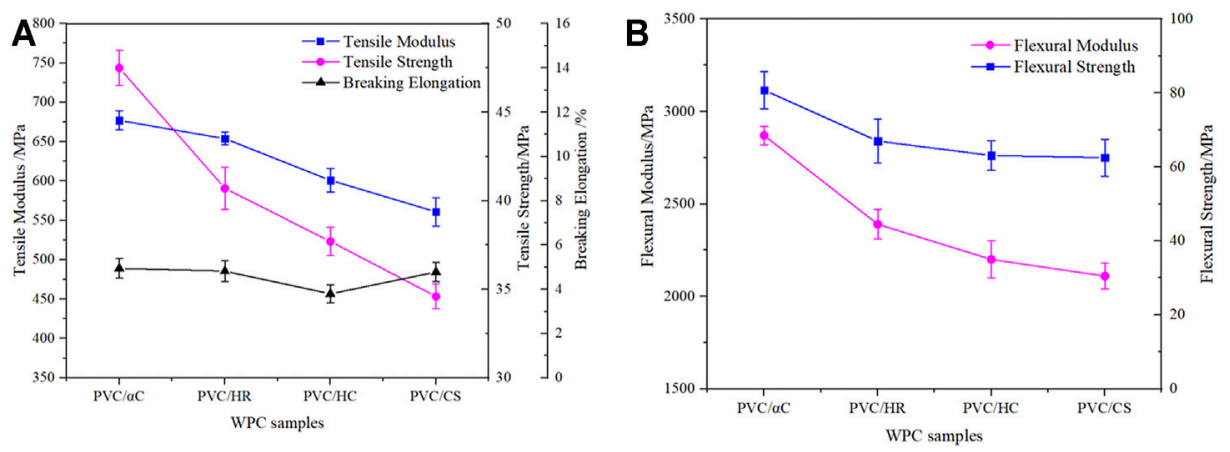

FIGURE 5 | Tensile properties and flexural properties of WPCs (A) Tensile results; (B) Flexural results.
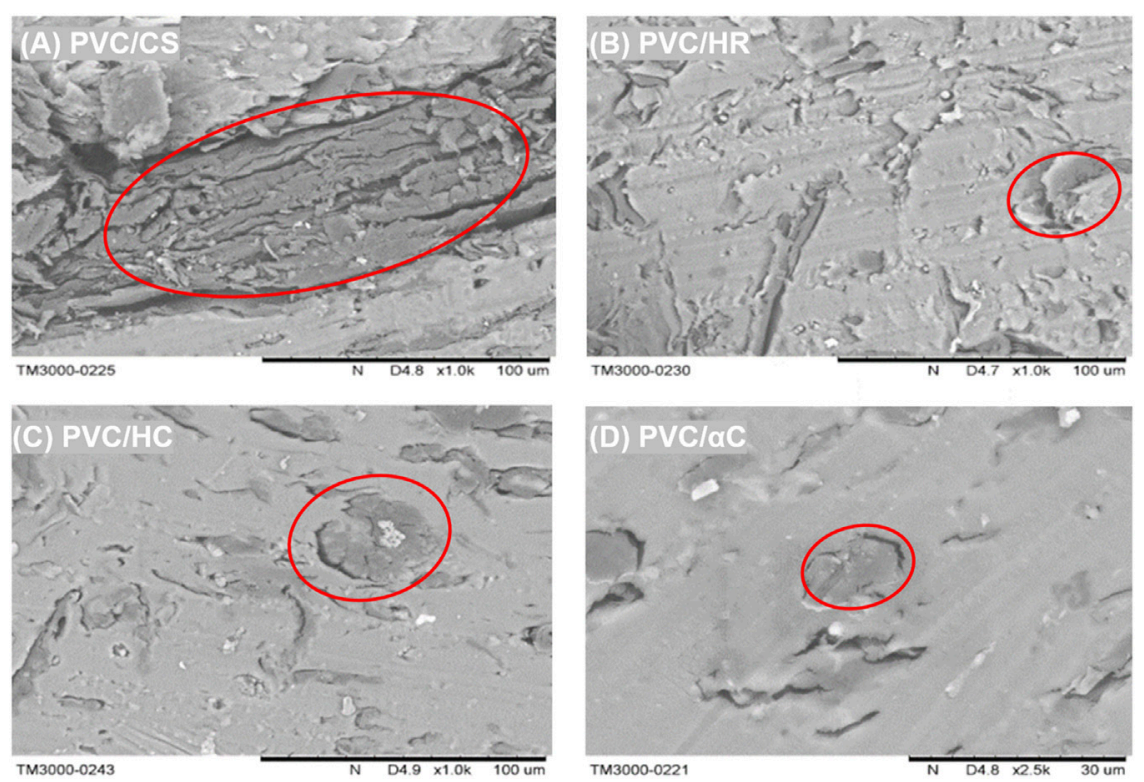

FIGURE 6 | SEM of WPCs (A) PVC/CS, (B) PVC/HR, (C) PVC/HC, and (D) PVC/aC with lignocellulosic domains circled. 

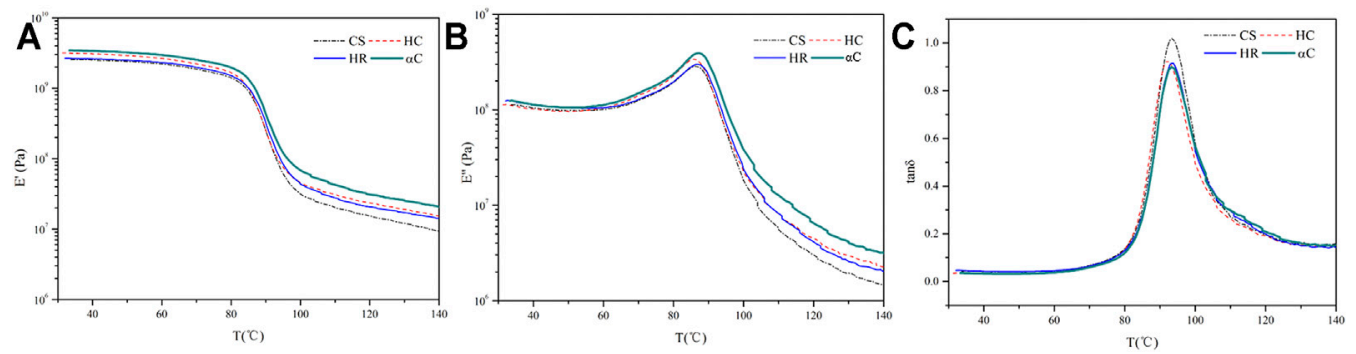

FIGURE 7 | DMA curves of WPCs (A) storage modulus $E^{\prime}$, (B) loss modulus $E^{\prime \prime}$, and (C) loss factor tan $\delta$.

TABLE 4 | Dynamic mechanical analysis data of WPC

\begin{tabular}{lcccc} 
& PVC/CS & PVC/HC & PVC/HR & PVC/aC \\
\hline$T_{\mathrm{g}}\left({ }^{\circ} \mathrm{C}\right)$ & 93.2 & 92.1 & 93.0 & 93.0 \\
$\tan \delta_{\max }$ & 1.01 & 0.93 & 0.92 & 0.89 \\
\hline
\end{tabular}

These improvements are highly related to the morphology of the fillers, as observed in Figure 4. aC has the highest content of crystalline cellulose and shows fibrous appearance with the highest aspect ratio and therefore acts as the most efficient reinforcement for stress transfer and load-bearing (Gibson, 2016). The PVC/HR sample gives superior mechanical properties than the $\mathrm{PVC} / \mathrm{HC}$ sample because $\mathrm{HR}$ has more fibrous structures, although not as fine and regular as aC.

We also studied the morphology of the lignocellulosic fillers in WPCs by SEM (Figure 6). The PVC/CS sample shows a coarse cross-section where a large block of $\mathrm{CS}$ can be found as circled in Figure 6A, whereas the rest samples, especially for the $\mathrm{PVC} / \mathrm{aC}$ sample, present smoother appearance with smaller filler domains, which suggests enhanced interfacial interactions between the lignocellulosic reinforcements and the PVC matrix, and this is crucial for the reinforcing effect in polymer composites. Lignin has been reported to have better compatibility with non-protonic polymers than the carbohydrate components due to its higher hydrophobicity ( $\mathrm{Li}$ et al., 2021). The leftover lignin after pretreatment was more exposed rather than well-assembled inside the origin lignocellulosic structure and therefore may perform as a compatibilizer to improve the interfacial adhesion. This may also explain why PVC/HC gives a relatively weak reinforcing effect, as in $\mathrm{HC}$, the lignin component is almost completely removed.

The dynamic mechanical properties of WPCs were studied via DMA, as shown in Figure 7. The storage modulus $\left(E^{\prime}\right)$ for all samples shows the same trend, which is staying relatively stable at the low-temperature range and decreasing rapidly at $>80^{\circ} \mathrm{C}$ due to the glass transition of PVC macromolecules. The loss modulus $\left(E^{\prime \prime}\right)$ and the loss factor $(\tan \delta)$ curves give a peak at the glass transition, and the peaked temperature $\left(T_{\mathrm{g}}\right)$ and maximum values for the $\tan \delta$ curves are listed in Table 4. The $T_{\mathrm{g}}$ for all samples appears at $92.1-93.2^{\circ} \mathrm{C}$, demonstrating that these micro-sized lignocellulosic fillers impose little influence on the glass transition behavior of PVC. The $\tan \delta_{\max }$ for PVC/CS is apparently higher than those for the rest samples, which confirms the poorer interfacial adhesion between PVC and CS as also presented in the SEM image (Figure 6). The friction at the interface of lower compatibility consumes more energy during dynamic stress-strain movement and therefore leads to a higher loss factor (Schirp and Wolcott, 2006; Fang et al., 2014).

\section{CONCLUSION}

In summary, we have optimized the alkaline-EtOH stewing process to selectively remove lignin from CS, achieving the HC sample, and explored the acid stewing process to selectively remove hemicellulose achieving the HR sample. These optimal processes were combined to pretreat $\mathrm{CS}$ obtaining the $\mathrm{aC}$ sample with both lignin and hemicellulose removed. The aC sample shows the highest degree of crystallinity (72.60\%) as estimated from X-ray diffraction analysis results and fibrous morphology with the highest aspect ratio as seen in SEM images. PVC-based WPCs with $\mathrm{CS}, \mathrm{HC}, \mathrm{HR}$, and $\mathrm{aC}$ fillers were prepared using the traditional thermal compounding process. Compared with PVC/CS, PVC/aC gives a substantial increase in tensile strength and modulus by 37.21 and $21.66 \%$ and flexural strength and modulus by 29.98 and $34.88 \%$, respectively. $\mathrm{PVC} / \mathrm{HR}$ and $\mathrm{PVC} / \mathrm{HC}$ also present superior mechanical properties than the PVC/CS sample. These improvements in mechanical properties lie in the reinforcing effect of a fibrous structure and the improved interfacial compatibility as proven by SEM and DMA results. Therefore, better than nature, the removal of lignin and hemicellulose can be one potential approach to prepare efficient reinforcements for PVC-based WPCs, and the extracted lignin and hemicellulose can be further developed to valuable biochemicals, which adds value into both WPC materials and biorefinery products.

\section{DATA AVAILABILITY STATEMENT}

The original contributions presented in the study are included in the article/Supplementary Material; further inquiries can be directed to the corresponding authors.

\section{AUTHOR CONTRIBUTIONS}

All authors listed have made a substantial, direct, and intellectual contribution to the work and approved it for publication. 


\section{FUNDING}

We would like to thank all the authors and the financial support by the National Key Research and Development Program of China (grant no. 2019YFD1101202), Jiangsu Province Natural Science Foundation for Young Scholars (grant no. SBK2021040275), Natural Science Foundation for Distinguished Young Scholars

\section{REFERENCES}

Alexy, P., Košíková, B., Crkonová, G., Gregorová, A., and Martiš, P. (2004). Modification of Lignin-Polyethylene Blends with High Lignin Content Using Ethylene-Vinylacetate Copolymer as Modifier. J. Appl. Polym. Sci. 94, 1855-1860. doi:10.1002/app.20716

Alvarez-Valencia, D., Dagher, H. J., Davids, W. G., Lopez-Anido, R. A., and Gardner, D. J. (2010). Structural Performance of Wood Plastic Composite Sheet Piling. J. Mater. Civ. Eng. 22 (12), 1235-1243. doi:10.1061/(ASCE)MT.19435533.0000132

Andreeßen, C., and Steinbüchel, A. (2019). Recent Developments in Nonbiodegradable Biopolymers: Precursors, Production Processes, and Future Perspectives. Appl. Microbiol. Biotechnol. 103, 143-157. doi:10.1007/s00253018-9483-6

Ashori, A., and Nourbakhsh, A. (2010). Performance Properties of Microcrystalline Cellulose as a Reinforcing Agent in Wood Plastic Composites. Compos. B. Eng. Comp. 41, 578-581. doi:10.1016/j.compositesb.2010.05.004

Ayrilmis, N., Jarusombuti, S., Fueangvivat, V., and Bauchongkol, P. (2011). Effect of Thermal-Treatment of Wood Fibres on Properties of Flat-Pressed Wood Plastic Composites. Polym. Degrad. Stab. 96, 818-822. doi:10.1016/ j.polymdegradstab.2011.02.005

Boerjan, W., Ralph, J., and Baucher, M. (2003). Lignin Biosynthesis. Annu. Rev. Plant Biol. 54, 519-546. doi:10.1146/annurev.arplant.54.031902.134938

Casenave, S., Ait-Kadi, A., and Brahimi, B. (1995). Properties of Highly Filled Lignin-Polyethylene Composite Materials Made by Catalytic Grafting. Annu. Tech. Conf. Soc. Plast. Eng. 53, 1438-1442.

Cazacu, G., Mihaies, M., Pascu, M. C., Profire, L., Kowarskik, A. L., and Vasile, C. (2004). Polyolefin/Lignosulfonate Blends, 9. Macromol. Mater. Eng. 289, 880-889. doi:10.1002/mame.200300378

Chaharmahali, M., Tajvidi, M., and Najafi, S. K. (2008). Mechanical Properties of Wood Plastic Composite Panels Made from Waste Fiberboard and Particleboard. Polym. Compos. 29, 606-610. doi:10.1002/pc.20434

Chen, J., Teng, Z., and Wu, J. (2017). Recycling of Waste FRP and Corn Straw in Wood Plastic Composite. Polym. Compos. 38, 2140-2145. doi:10.1002/pc.23789

Chen, X., Cao, X., Sun, S., Yuan, T., Wang, S., Shi, Q., et al. (2019). Hydrothermal Acid Hydrolysis for Highly Efficient Separation of Lignin and Xylose from PreHydrolysis Liquor of Kraft Pulping Process. Sep. Purif. Tech. 209, 741-747. doi:10.1016/j.seppur.2018.09.032

Chen, J., Zou, Y., Ge, H., Cui, Z., and Liu, S. (2018). Mechanical and Water Absorption Behaviors of Corn Stalk/Sisal Fiber-Reinforced Hybrid Composites. J. Appl. Polym. Sci. 135, 46405. doi:10.1002/app.46405

Chen, X., Li, H., Sun, S., Cao, X., and Sun, R. (2018). Co-Production of Oligosaccharides and Fermentable Sugar from Wheat Straw by Hydrothermal Pretreatment Combined with Alkaline Ethanol Extraction. Ind. Crops Prod. 111, 78-85. doi:10.1016/j.indcrop.2017.10.014

Enayati, A. A., Hosseinaei, O., Wang, S., Mirshokraie, S. A., and Tajvidi, M. (2009). Thermal Properties of Wood-plastic Composites Prepared from Hemicellulose-Extracted Wood Flour. Iran. J. Polym. Sci. Technol. 22, 171-181. doi:10.22063/JIPST.2013.633

Fang, L., Chang, L., Guo, W.-j., Chen, Y., and Wang, Z. (2014). Influence of Silane Surface Modification of Veneer on Interfacial Adhesion of Wood-Plastic Plywood. Appl. Surf. Sci. 288, 682-689. doi:10.1016/j.apsusc.2013.10.098

Gibson, R. F. (2016). Principles of Composite Material Mechanics. 4th Eds. Florida: CRC Press.

Hao, X., Zhou, H., Mu, B., Chen, L., Guo, Q., Yi, X., et al. (2020). Effects of Fiber Geometry and Orientation Distribution on the Anisotropy of Mechanical Properties, Creep Behavior, and Thermal Expansion of Natural Fiber/HDPE (grant no. SBK20190035), Program of National Natural Science Foundation of China (grant nos. 22178170, 21878142, 22008119, and 21908100), Key Research and Development Plan of Jiangsu Province (grant no. BE2020712 and BE2019001), Six Talent Peaks Project in Jiangsu Province (SWYY-045), and High-Level Innovation and Entrepreneurship Talents Introduction Program of Jiangsu Province.

Composites. Composites B: Eng. 185, 107778. doi:10.1016/ j.compositesb.2020.107778

Hosseinaei, O., Wang, S., Enayati, A. A., and Rials, T. G. (2012). Effects of Hemicellulose Extraction on Properties of Wood Flour and Wood-Plastic Composites. Composites A: Appl. Sci. Manufacturing 43, 686-694. doi:10.1016/j.compositesa.2012.01.007

Kazayawoko, M., Balatinecz, J. J., and Matuana, L. M. (1999). Surface Modification and Adhesion Mechanisms in Wood Fiber-Polypropylene Composites. I. Mater. Sci. 34, 6189-6199. doi:10.1023/A:1004790409158

Kharade, A. Y., and Kale, D. D. (1999). Lignin-Filled Polyolefins. J. Appl. Polym. Sci. 72, 1321-1326. doi:10.1002/(sici)1097-4628(19990606)72:10<1321::aid-app12>3.0.co;2-9

Li, M., Sun, X., Chen, Y., Shen, T., Tan, Z., Tang, C., et al. (2020). Effect of Xylan Sulfate on the Responsive Swelling Behavior of Poly(Methacrylatoethyl Trimethyl Ammonium Chloride)-Based Composite Hydrogels. Cellulose 27, 8745-8756. doi:10.1007/s10570-020-03402-4

Li, M., Jia, Y., Shen, X., Shen, T., Tan, Z., Zhuang, W., et al. (2021). Investigation into Lignin Modified PBAT/Thermoplastic Starch Composites: Thermal, Mechanical, Rheological and Water Absorption Properties. Ind. Crops Prod. 171, 113916. doi:10.1016/j.indcrop.2021.113916

Liminana, P., Garcia-Sanoguera, D., Quiles-Carrillo, L., Balart, R., and Montanes, N. (2018). Development and Characterization of Environmentally Friendly Composites from Poly(butylene Succinate) (PBS) and almond Shell Flour with Different Compatibilizers. Composites Part B: Eng. 144, 153-162. doi:10.1016/ j.compositesb.2018.02.031

Liu, R., Cao, J., and Peng, Y. (2014). Influences of Wood Components on the Property of Wood-Plastic Composites. Chem. Ind. Eng. Prog. 33, 2072-2083. doi:10.3969/j.issn.1000-6613.2014.08.023

Liu, Y., Guo, L., Wang, W., Sun, Y., and Wang, H. (2019). Modifying Wood Veneer with Silane Coupling Agent for Decorating Wood Fiber/High-Density Polyethylene Composite. Construction Building Mater. 224, 691-699. doi:10.1016/j.conbuildmat.2019.07.090

Maldhure, A. V., Ekhe, J. D., and Deenadayalan, E. (2012). Mechanical Properties of Polypropylene Blended with Esterified and Alkylated Lignin. J. Appl. Polym. Sci. 125, 1701-1712. doi:10.1002/app.35633

Michell, A. J., Vaughan, J. E., and Willis, D. (1978). Wood Fiber-Synthetic Polymer Composites. II. Laminates of Treated Fibers and Polyolefins. J. Appl. Polym. Sci. 22, 2047-2061. doi:10.1002/app.1978.070220724

Mu, B., Tang, W., Liu, T., Hao, X., Wang, Q., and Ou, R. (2021). Comparative Study of High-Density Polyethylene-Based Biocomposites Reinforced with Various Agricultural Residue Fibers. Ind. Crops Prod. 172, 114053. doi:10.1016/ j.indcrop.2021.114053

Nascimento, V. M., Nakanishi, S. C., Rocha, G. J. M., Rabelo, S. C., Pimenta, M. T. B., and Rossell, C. E. V. (2016). Effect of Anthraquinone on Alkaline Pretreatment and Enzymatic Kinetics of Sugarcane Bagasse Saccharification: Laboratory and Pilot Scale Approach. ACS Sust. Chem. Eng. 4, 3609-3617. doi:10.1021/acssuschemeng.5b01433

Nourbakhsh, A., and Ashori, A. (2010). Wood Plastic Composites from AgroWaste Materials: Analysis of Mechanical Properties. Bioresour. Tech. 101, 2525-2528. doi:10.1016/j.biortech.2009.11.040

Ouajai, S., and Shanks, R. A. (2005). Composition, Structure and Thermal Degradation of Hemp Cellulose after Chemical Treatments. Polym. Degrad. Stab. 89, 327-335. doi:10.1016/j.polymdegradstab.2005.01.016

Petchwattana, N., Covavisaruch, S., and Sanetuntikul, J. (2012). Recycling of WoodPlastic Composites Prepared from Poly(Vinyl Chloride) and Wood Flour. Construction Building Mater. 28, 557-560. doi:10.1016/j.conbuildmat.2011.08.024

Qi, R., He, C., and Jin, Q. (2021). Accelerated Weathering of Polyvinyl ChlorideBased Wood-Plastic Composites: Effect of Plant Species. BioRes 16, 5261-5271. doi:10.15376/biores.16.3.5261-5271 
Quiles-Carrillo, L., Montanes, N., Jorda-Vilaplana, A., Balart, R., and Torres-Giner, S. (2019). A Comparative Study on the Effect of Different Reactive Compatibilizers on Injection-Molded Pieces of Bio-Based High-Density Polyethylene/Polylactide Blends. J. Appl. Polym. Sci. 136, 47396. doi:10.1002/ APP.47396S1361

Schirp, A., and Wolcott, M. P. (2006). Fungal Degradation of Wood-Plastic Composites and Evaluation Using Dynamic Mechanical Analysis. J. Appl. Polym. Sci. 99, 3138-3146. doi:10.1002/app.22945

Segal, L., Creely, J. J., Martin, A. E., Jr., and Conrad, C. M. (1959). An Empirical Method for Estimating the Degree of Crystallinity of Native Cellulose Using the X-Ray Diffractometer. Textile Res. J. 29, 786-794. doi:10.1177/ 004051755902901003

Shen, T., Hu, Y., Hu, R., Zhuang, W., Li, M., Niu, H., et al. (2020). Continuous Production of Furfural from Pulp Prehydrolysate in a Vaporization Reactor. Ind. Crops Prod. 153, 112565. doi:10.1016/j.indcrop.2020.112565

Sluiter, A., Hames, B., Ruiz, R., Scarlata, C., Sluiter, J., Templeton, D., et al. (2008). Determination of Structural Carbohydrates and Lignin in Biomass. Technical report of Laboratory Analytical Procedure NREL/TP-510-42618.

Sun, Y., Guo, L., Liu, Y., Wang, W., and Song, Y. (2019). Glue Wood Veneer to Wood-Fiber-High-Density-Polyethylene Composite. Int. J. Adhes. Adhesives 95, 102444. doi:10.1016/j.ijadhadh.2019.102444

Sun, S.-C., Sun, D., Li, H.-Y., Cao, X.-F., Sun, S.-N., and Wen, J.-L. (2021). Revealing the Topochemical and Structural Changes of Poplar Lignin during a Two-Step Hydrothermal Pretreatment Combined with Alkali Extraction. Ind. Crops Prod. 168, 113588. doi:10.1016/j.indcrop.2021.113588

Szabó, G., Kun, D., Renner, K., and Pukánszky, B. (2018). Structure, Properties and Interactions in Ionomer/Lignin Blends. Mater. Des. 152, 129-139. doi:10.1016/ j.matdes.2018.04.050

Tahir, N., Bhatti, H. N., Iqbal, M., and Noreen, S. (2017). Biopolymers Composites with Peanut Hull Waste Biomass and Application for Crystal Violet Adsorption. Int. J. Biol. Macromolecules 94, 210-220. doi:10.1016/j.ijbiomac.2016.10.013

Tang, C., Shan, J., Chen, Y., Zhong, L., Shen, T., Zhu, C., et al. (2017). Organic Amine Catalytic Organosolv Pretreatment of Corn stover for Enzymatic Saccharification and High-Quality Lignin. Bioresour. Tech. 232, 222-228. doi:10.1016/j.biortech.2017.02.041

Tian, G., Zhuang, J., Fu, Y., Wang, Z., and Li, Q. (2009). Enhanced Mechanical Strength of Polyethylene-Based Lignocellulosic-Plastic
Composites by Cellulose Fibers. BioResources 14, 1668-1678. doi:10.15376/biores.14.1.1668-1678

Tserki, V., Zafeiropoulos, N. E., Simon, F., and Panayiotou, C. (2005). A Study of the Effect of Acetylation and Propionylation Surface Treatments on Natural Fibres. Composites Part A: Appl. Sci. Manufacturing 36 (8), 1110-1118. doi:10.1016/j.compositesa.2005.01.004

Yim, H., and Kim, D. S. (2012). Physical Properties of PVC/Aminosilane-Treated Wood Flour/Organoclay Composites. Polym. Adv. Technol. 23, 1441-1445. doi:10.1002/pat.2065

Zhong, L., Zhang, X., Tang, C., Chen, Y., Shen, T., Zhu, C., et al. (2018). Hydrazine Hydrate and Organosolv Synergetic Pretreatment of Corn Stover to Enhance Enzymatic Saccharification and Co-Production of High-Quality Antioxidant Lignin. Bioresour. Tech. 268, 677-683. doi:10.1016/j.biortech.2018.08.063

Zong, G., Hao, X., Hao, J., Tang, W., Fang, Y., Ou, R., et al. (2020). High-Strength, Lightweight, Co-Extruded Wood Flour-Polyvinyl Chloride/lumber Composites: Effects of Wood Content in Shell Layer on Mechanical Properties, Creep Resistance, and Dimensional Stability. J. Clean. Prod. 244, 118860. doi:10.1016/j.jclepro.2019.118860

Conflict of Interest: The authors declare that the research was conducted in the absence of any commercial or financial relationships that could be construed as a potential conflict of interest.

Publisher's Note: All claims expressed in this article are solely those of the authors and do not necessarily represent those of their affiliated organizations, or those of the publisher, the editors and the reviewers. Any product that may be evaluated in this article, or claim that may be made by its manufacturer, is not guaranteed or endorsed by the publisher.

Copyright (c) 2022 Shen, Li, Zhang, Zhong, Lin, Yang, Li, Zhuang, Zhu and Ying This is an open-access article distributed under the terms of the Creative Commons Attribution License (CC BY). The use, distribution or reproduction in other forums is permitted, provided the original author(s) and the copyright owner(s) are credited and that the original publication in this journal is cited, in accordance with accepted academic practice. No use, distribution or reproduction is permitted which does not comply with these terms. 